\title{
Isosceles Triangular Resonator Based Compact Triple Band Quad Element Multi Terminal Antenna
}

\author{
Sk Nurul ISLAM, Santanu DAS \\ Dept. of Electronics and Tele-Comm. Engineering, Indian Inst. of Engineering Science and Technology, Shibpur \\ Howrah-711103, West Bengal, India \\ badshaays@gmail.com, santanumdas@yahoo.com
}

Submitted June 14, 2019 / Accepted November 26, 2019

\begin{abstract}
A triple band quad element multi-input-multioutput (MIMO) antenna is proposed for Bluetooth (2.4 GHz), WLAN (2.5/4.9 GHz) and LTE (3.7 GHz) applications. A compact triangular ring-shaped structure is used as an antenna element. An isosceles triangular ring resonator is designed in such a way that it offers dual-band and another ring resonator is placed inside the empty space of the first resonator to obtain the third band. The antenna element is studied in terms of $\left|S_{11}\right|$ and also the current distributions are observed at three resonance frequencies to find out the resonance mechanism. The proposed quad element MIMO antenna is compact in total area $\left(0.45 \lambda_{0} \times 0.45 \lambda_{0}\right)$. Isolation better than $20 \mathrm{~dB}$ is achieved with minimum inter-element spacing of $0.07 \lambda_{0}$ without extra isolation circuit. Gain, radiation patterns, envelope correlation coefficient (ECC), diversity gain (DG), channel capacity loss (CCL) and total active reflection coefficient (TARC) values are studied to comprehend the MIMO performance of the proposed design.
\end{abstract}

\section{Keywords}

Isosceles triangular ring resonator, triple band antenna, MIMO antenna, isolation

\section{Introduction}

In the present scenario, smart device requires multiple bands with high data rate for different application which can be accomplished by multiple antennas with multiple operating bands like LTE, Bluetooth, WLAN, GPS, GPRS, etc. Multi-input-multi-output (MIMO) antenna becomes the first choice for the makers of communication device to achieve high data rate and less multipath fading effect [1]. However, MIMO antenna need large area in order to reduce the mutual coupling between antenna elements. Thus, it is very important to reduce the inter-element spacing of MIMO antenna to make the device size user friendly without degrading the isolation between ports. Various designs of MIMO antenna are reported in recent years towards compactness of the antenna size. An ultra-wide band antenna is proposed in [2] for MIMO applications and elec- tromagnetic band gap (EBG) structure is used in order to achieve proper isolation between antenna elements. EBG structure needs via which leads to design complexity. Dualband two element MIMO antenna is presented in [3], slots are etched on ground plane to improve isolation. In [4], a dual element dual-band antenna is proposed for MIMO applications, however, isolation is less in the first band of operation. A multiband MIMO antenna is proposed for $\mathrm{C}$ and $\mathrm{X}$ band applications in [5], Defected ground structure (DGS) technique is used to enhance the isolation. In [6], T. Kumari et al. proposed a dual band dielectric resonator (DR) based MIMO antenna and DGS technique is used in order to achieve significant isolation. D. Sarkar and K. V. Srivastava proposed a split ring resonator (SRR) based dual band antenna for MIMO applications [7]. A triple band antenna is proposed in [8] and a defect is introduced on ground plane to achieve more isolation. In [9], a triple band MIMO antenna for GSM900/1800 and LTE2600 application is proposed; a winding meandered line structures and T-shaped slot are used in order to enhance isolation. In [10], a two-element triple band MIMO antenna is proposed and it contains one notched band. A modified inter-digital capacitor (MIDC) is introduced in between two antenna elements in order to improve isolation. A circularly polarized two elements MIMO antenna is proposed in [11] in which a grounded slit is used to achieve good isolation. A triple band MIMO antenna is proposed in [12] with independent tunable characteristics. In most of the previous works different type of isolation circuit is introduced to maintain the proper isolation in multiple bands which increases the design complexity.

This paper presents a triple band quad element MIMO antenna for Bluetooth, WLAN and LTE operations with a compact area with proper isolation. The antenna element consists of two triangular split ring resonators, is modeled in such a way that it occupies minimum area. The resonance frequencies are observed at $2.5 \mathrm{GHz}, 3.7 \mathrm{GHz}$ and $4.9 \mathrm{GHz}$. The proposed MIMO gives satisfactory radiation pattern at three resonances with cross polar performance better than $30 \mathrm{~dB}$. Orthogonal arrangement of antenna element provides isolation between two consecutive ports better than $20 \mathrm{~dB}$ without using extra isolation network. ECC, DG, CCL and TARC values satisfy the MIMO per- 
formances. Simple configuration and compact size with triple band operation and significant performances in MIMO applications reveal its novelty.

Unit element antenna design and analysis are presented in Sec. 2. MIMO antenna design is described in Sec. 3. In Sec. 4, fabrication and measurement results are discussed. Diversity performance is discussed in Sec. 5 and the paper is finally concluded in Sec. 6 .

\section{Antenna Design and Analysis}

The design and analysis of unit element of the MIMO antenna is discussed in this section. Unit element configuration is inspired and extended from authors' previous work given in [13]. A substrate with relative permittivity 4.4, loss tangent 0.02 and $1.58 \mathrm{~mm}$ height is chosen to design the antenna and the schematic diagram is shown in Fig. 1. All dimensions are mentioned in Fig. 1. The antenna is fed by a $50 \Omega$ microstrip line through a matching line [12]. The design steps to achieve triple band antenna are elaborated in three steps as shown in Fig. 2(a) and the corresponding $\left|\mathrm{S}_{11}\right|$ are plotted in Fig. 2(b). In the first step, an isosceles triangular ring resonator (ITRR) is designed as Ant-A, shown in Fig. 2(a) which provides single resonance. Then, a slot is etched on either one of the two equal legs of the ITRR, denoted as Ant-B to achieve dual resonances. Lastly, a modified triangular split ring resonator is placed inside the empty space of the ITRR and the whole structure provides triple band response. First and second bands are shifted towards lower frequency due to the incorporation of the second resonator as there is an electromagnetic coupling between the two resonators. A parametric study is done on Ant-B by varying the slot position. Here, $\left|S_{11}\right|$ for

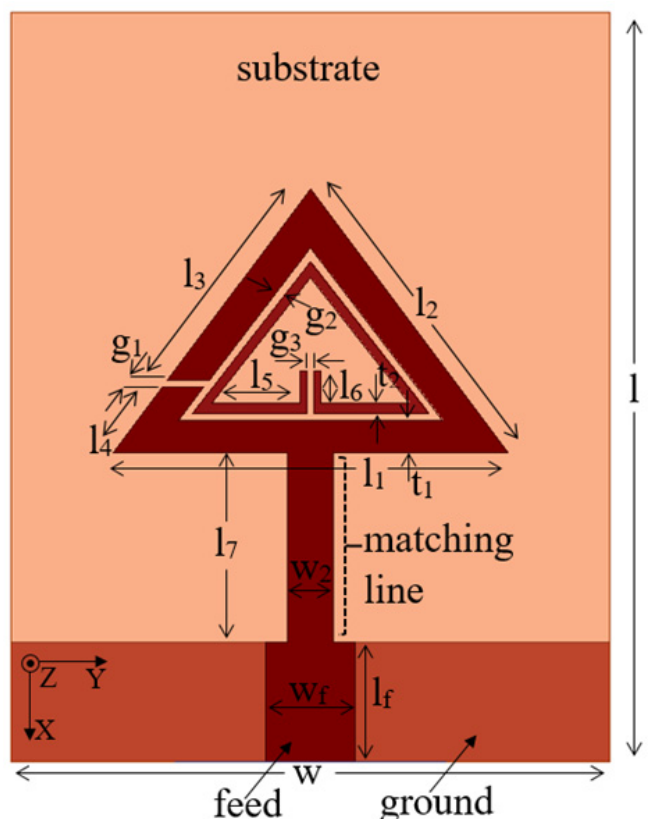

Fig. 1. Schematic of the proposed triple band antenna $(\mathrm{w}=20$, $\mathrm{l}=25,1_{1}=13.2,1_{2}=11, \mathrm{w}_{2}=1.5,1_{3}=8,1_{4}=2.75,1_{5}=3,1_{6}=1.1$, $1_{7}=6.3,1_{\mathrm{f}}=4, \mathrm{w}_{\mathrm{f}}=3, \mathrm{~g}_{1}=0.25, \mathrm{~g}_{2}=0.25, \mathrm{~g}_{3}=0.25, \mathrm{t}_{1}=1$, $\mathrm{t}_{2}=0.3, \mathrm{t}_{3}=0.25$ (all dimensions are in $\left.\mathrm{mm}\right)$ ). four different slot positions ( $\left.\mathrm{P}_{-} \mathrm{A} / \mathrm{P} \mathrm{B}_{-} \mathrm{P}_{-} \mathrm{C} / \mathrm{P} \_\mathrm{D}\right)$ and without slot are presented in Fig. $2(\mathrm{c})$. From this figure, it is observed that a slot at $\mathrm{P}_{-} \mathrm{A} / \mathrm{P} \mathrm{B}_{-} \mathrm{P}_{-} \mathrm{C}$ generates dual band as the slot makes two different current paths, path-1 and path-2. At resonances, both paths are equal to half guided wavelength $\left(\lambda_{\mathrm{g}} / 2\right)$. It is also noticed that the first band is shifted towards higher frequency and the second band is shifted towards lower frequency when slot position moves from $\mathrm{P}_{-} \mathrm{A}$ to $\mathrm{P} \_\mathrm{C}$ through $\mathrm{P} \mathrm{B}_{-}$. The possible reason could be the length of path- 1 is decreased whereas length of path2 is increased. A slot on apex i.e at P_D is etched and the antenna offers single band as like Ant-A (without slot). However, the resonance is shifted slightly towards lower frequency. Possible reason for this shifting is the capacitive effect for the split on P_D.

Current distribution at three resonance frequencies are plotted in Fig. 3(a)-(c) for further confirmation of current path of each resonance. Path-1 is responsible for the first resonance at $2.5 \mathrm{GHz}$ as maximum current is concentrated
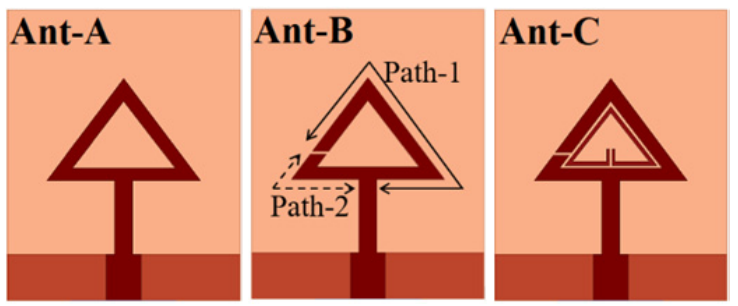

(a)

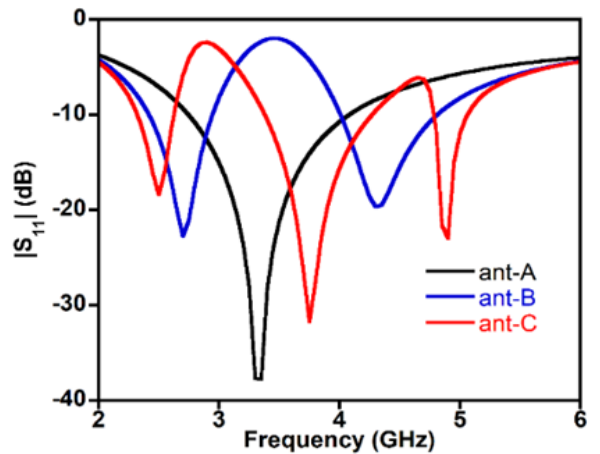

(b)

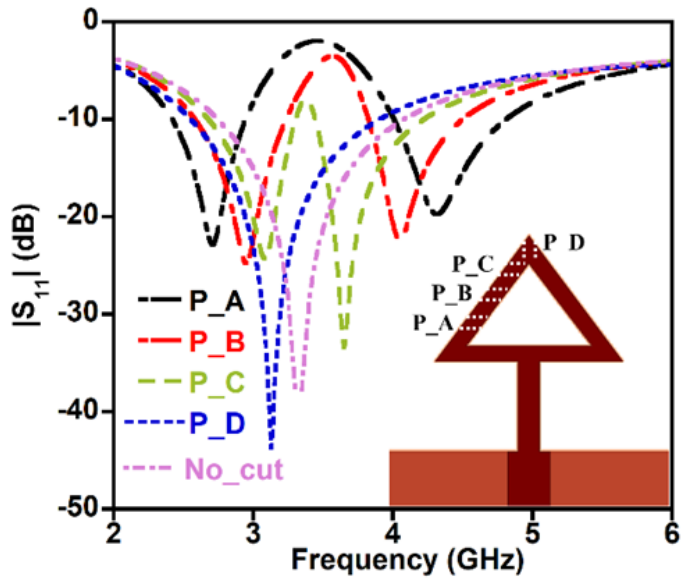

(c)

Fig. 2. Antenna configuration and response: (a) Design steps. (b) $\left|S_{11}\right|$ of the three antennas. (c) $\left|S_{11}\right|$ plot with the variation of slot position for outer ring only. 


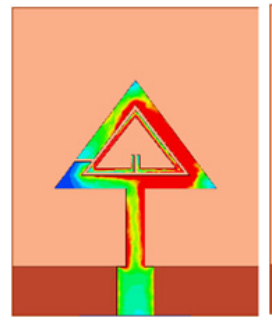

(a)

(c)

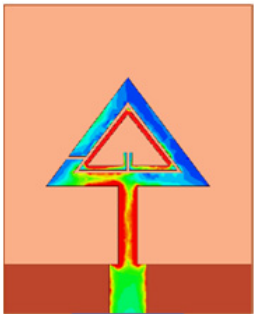

(b)

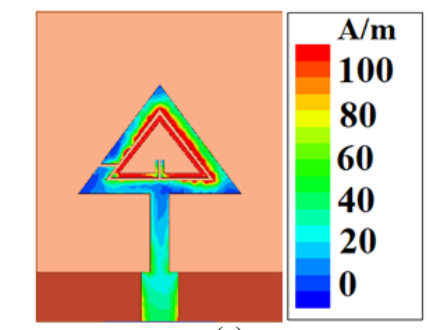

Fig. 3. Surface current distribution $(\mathrm{A} / \mathrm{m})$ at (a) $2.5 \mathrm{GHz}$, (b) $3.7 \mathrm{GHz}$, (c) $4.9 \mathrm{GHz}$.

on path-1 as shown in Fig. 3(a). The second resonance at $3.7 \mathrm{GHz}$ occurred due to the path-2 and the second resonator, evident from the current distribution plot in Fig. 3(b). Figure 3(c) reveals that maximum current is observed on the second resonator which confirms that the second resonator is responsible for generation of the third resonance at $4.9 \mathrm{GHz}$.

\section{Quad Element MIMO Antenna}

The triple band antenna discussed in Sec. 2 is used to realize a quad element MIMO antenna as shown in Fig. 4. By virtue of negligible cross-polar level of the unit element, substantial isolation (less than $30 \mathrm{~dB}$ ) between them can be achieved by placing two consecutive antennas orthogonally, which in turn will mitigate the area of the MIMO antenna. As four elements of the MIMO antenna are symmetric and placed symmetrically, only four S-parameters $\left(\left|\mathrm{S}_{11}\right|,\left|\mathrm{S}_{21}\right|,\left|\mathrm{S}_{31}\right|\right.$ and $\left.\left|\mathrm{S}_{41}\right|\right)$ out of sixteen are presented in Fig. 4(b) by exciting antenna \#1. Excitation of the other antenna element provides overlapping S-parameters. From $\left|\mathrm{S}_{11}\right|$ response of the proposed MIMO antenna, it is verified that resonance frequencies and the operating bandwidth remain almost similar to the unit antenna element. As shown from Fig. 4(b), $\left|\mathrm{S}_{21}\right|$ and $\left|\mathrm{S}_{41}\right|$ are similar as antenna element \#2 and \#4 are positioned identically with respect to antenna element $\# 1$.

\section{Fabrication and Measurement}

To validate the simulation performance of the proposed MIMO antenna, a prototype is fabricated on FR4 substrate of height of $1.58 \mathrm{~mm}$ as shown in Fig. 5(a). The S-parameters are measured with the help of a vector network analyzer (Agilent N5230A) and depicted in Fig. 5(b). It is observed that the results are in a good agreement with simulation. The resonances are observed at $2.4 \mathrm{GHz}$,

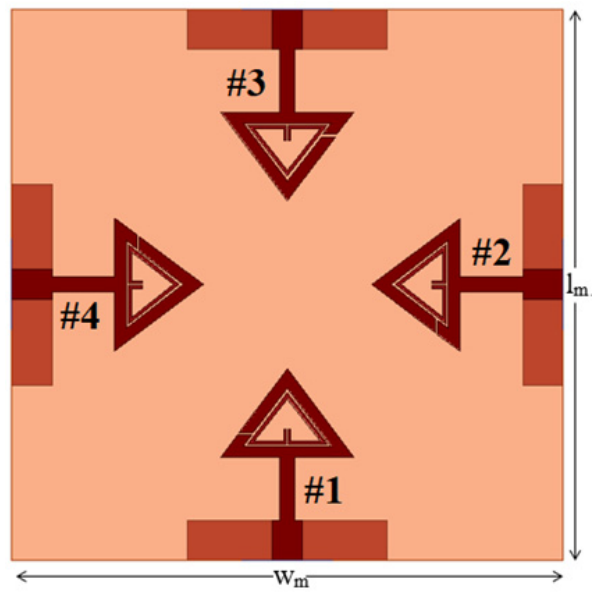

(a)

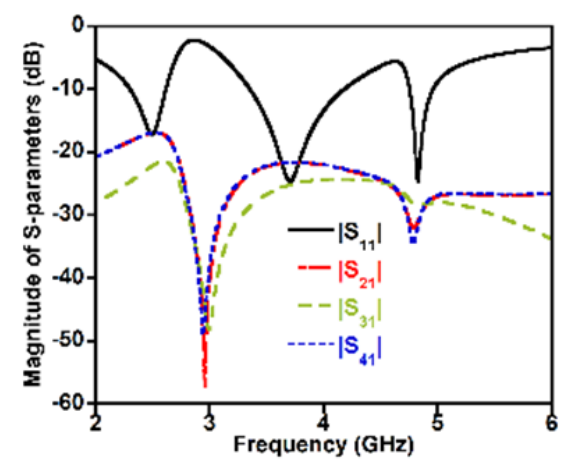

(b)

Fig. 4. Four element MIMO antenna: (a) Orientation $\left(1_{\mathrm{m}}=\mathrm{w}_{\mathrm{m}}=55 \mathrm{~mm}\right)$. (b) Simulated S-parameters.

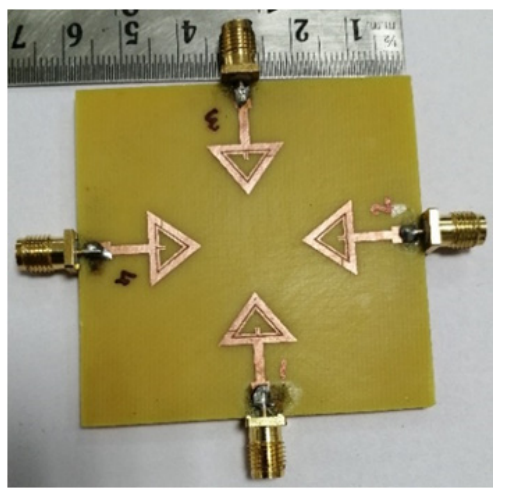

(a)

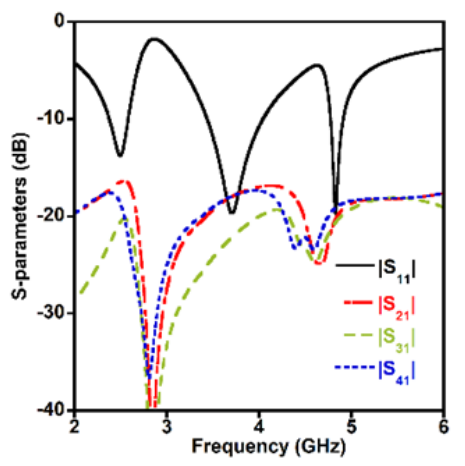

(b)

Fig. 5. MIMO antenna: (a) Fabricated prototype. (b) Measured S-parameters. 
$3.75 \mathrm{GHz}, \quad 4.95 \mathrm{GHz}$ with a bandwidth of $300 \mathrm{MHz}$, $820 \mathrm{MHz}$ and $200 \mathrm{MHz}$ respectively and isolations are better than $20 \mathrm{~dB}$.

Far-field radiation patterns are measured in both $\mathrm{XZ}$ and $\mathrm{YZ}$ plane and normalized values are plotted in Fig. 6 along with simulated results at three resonance frequencies. The patterns are omnidirectional with good cross-polar performance (better than $25 \mathrm{~dB}$ ). Gain of $0.6 \mathrm{dBi}, 1 \mathrm{dBi}$ and $0.8 \mathrm{dBi}$ are observed at $2.5 \mathrm{GHz}, 3.7 \mathrm{GHz}$ and $4.9 \mathrm{GHz}$ frequencies respectively. In Fig. 6(c), a $10^{\circ}$ inclination in the radiation pattern at the third resonance is observed due to the excitation of higher order modes of isosceles triangular (outer) resonator.

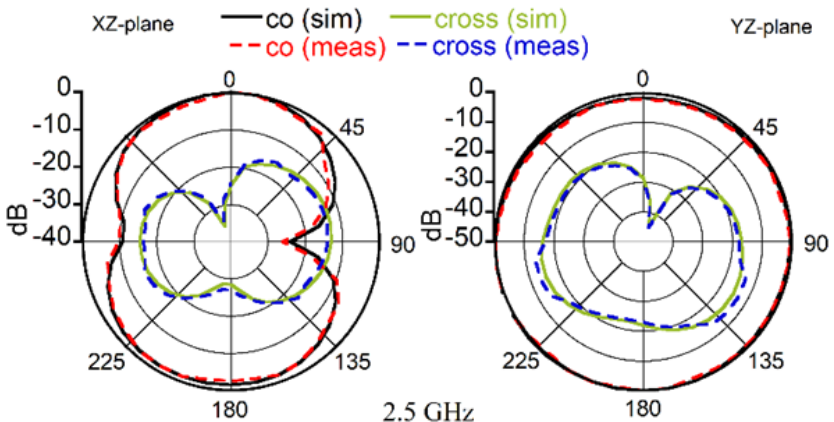

(a)

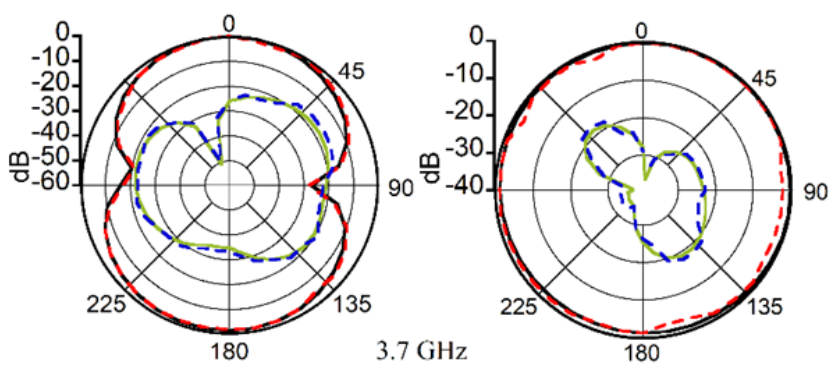

(b)

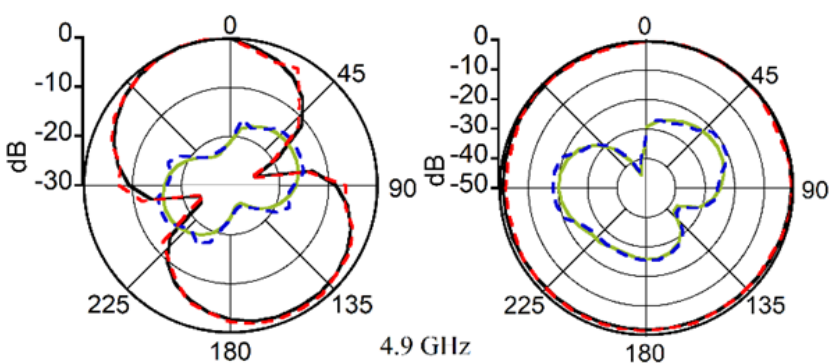

(c)

Fig. 6. Far field radiation patterns at (a) $2.5 \mathrm{GHz}$, (b) $3.7 \mathrm{GHz}$ and (c) $4.9 \mathrm{GHz}$

\section{Diversity Performance}

Isolation and radiation patterns are not the only parameters to conclude about the performance of a MIMO antenna. Diversity performance plays a big roll to determine the MIMO antenna performance. In this section, diversity performance is discussed in terms of ECC, DG, CCL and TARC.
ECC provides information of correlation between the radiation patterns of two antenna elements. ECC can be calculated by the following procedure given in [14].

$$
\begin{aligned}
& \rho_{\mathrm{e}, i j} \cong\left|\rho_{\mathrm{c}, i j}\right|^{2}= \\
& \left|\frac{\iint\left(X P R \cdot E_{\theta i} \cdot E_{\theta j}^{*} \cdot P_{\theta}+E_{\phi i} \cdot E_{\phi j}^{*} \cdot P_{\phi}\right) \mathrm{d} \Omega}{\sqrt{\iint\left(X P R \cdot G_{\theta i} \cdot P_{\theta}+G_{\phi i} \cdot P_{\phi}\right) \mathrm{d} \Omega \iint\left(X P R \cdot G_{\theta j} \cdot P_{\theta}+G_{\phi j} \cdot P_{\phi}\right) \mathrm{d} \Omega}}\right|^{2} .
\end{aligned}
$$

Here, $X P R, \Omega, E_{\theta}(\Omega), E_{\phi}(\Omega)$ represent cross polarization power ratio of incident wave, solid angle, $\theta$ and $\phi$ components of active electric field. $\theta$ and $\phi$ components of angular density of incoming plane waves are denoted by $P_{\theta}$ and $P_{\phi} . P_{\theta}=P_{\phi}=1 /(4 \pi)$ and $X P R=1$ are considered in certain propagation environment. $G_{\theta}$ and $G_{\phi}$ stand for $\theta$ and $\phi$ polarised signal realised active gain patterns. The following equations relate active gain patterns and electric field components: $G_{\theta i}=E_{\theta i} \cdot E_{\theta i}{ }^{*}, G_{\theta j}=E_{\theta j} \cdot E_{\theta j}{ }^{*}, G_{\phi i}=E_{\phi i} \cdot E_{\phi i}{ }^{*}$, and $G_{\phi j}=E_{\phi j} \cdot E_{\phi j}{ }^{*}$.

So, equation (1) can be written as

$$
\rho_{\mathrm{e}, i j}=\left|\frac{\iint\left(E_{\theta i} \cdot E_{\theta j}^{*}+E_{\phi i} \cdot E_{\phi j}^{*}\right) \mathrm{d} \Omega}{\sqrt{\iint\left(E_{\theta i} \cdot E_{\theta i}^{*}+E_{\phi i} \cdot E_{\phi i}^{*}\right) \mathrm{d} \Omega \iint\left(E_{\theta j} \cdot E_{\theta j}^{*}+E_{\phi j} \cdot E_{\phi j}^{*}\right) \mathrm{d} \Omega}}\right|^{2} .
$$

ECC calculation from far field parameters is very complex and time-consuming process. Broadband ECC can be calculated from S-parameters when it is considered that incoming signal is plane wave and antennas are well matched and lossless [15]. Although S-parameters do not provide any information of radiation pattern, it is significantly accurate when the MIMO antenna is placed in free space. The following equation provides ECC by using S-parameters.

$$
\rho_{\mathrm{e}, i j}=\frac{\left|\sum_{n=1}^{N} S_{i n}^{*} S_{n j}\right|^{2}}{\left(1-\left.\left|\sum_{n=1}^{N}\right| S_{n i}\right|^{2}\right)\left(1-\left.\left|\sum_{n=1}^{N}\right| S_{n j}\right|^{2}\right)} .
$$

The derived ECC by post processing the simulated and measured S-parameters are shown in Fig. 7 and it is found that the ECC values at three bands are very less compared to diversity thumb rule value of 0.5 .

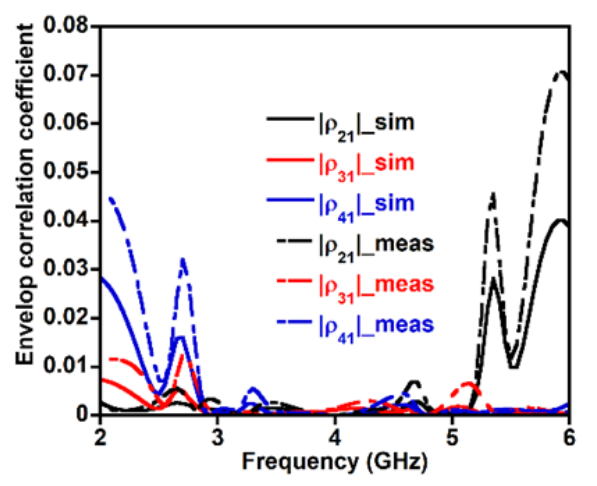

Fig. 7. ECC plots of the proposed antenna. 


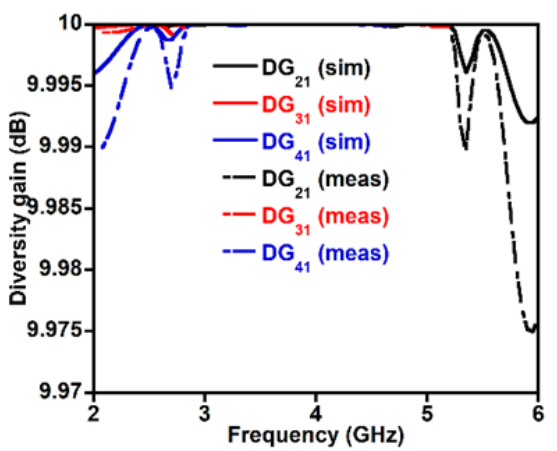

Fig. 8. Diversity gain plots of the proposed antenna.

Diversity gain refers the signal to noise ratio improvement respect to single antenna. DG is calculated using (4) in [2] and plotted in Fig. 8.

$$
D G=10 \sqrt{1-E C C^{2}} .
$$

The calculated DG values from simulated and measured ECC are almost $10 \mathrm{~dB}$ which validate the application of this antenna.

Channel capacity loss measures the loss of channel capacity due to the correlation between two antenna elements. Lesser CCL offers better performance and it can be calculated by (5-8) in [2]. The calculated CCL from the simulated and measured data are shown in Fig. 9. This figure reveals that the $\mathrm{CCL}$ values are $0.15,0.12$ and $0.25 \mathrm{bits} / \mathrm{sec} / \mathrm{Hz}$.

$$
\begin{gathered}
C_{\text {loss }}=-\log _{2}\left(\psi^{R}\right), \\
\psi^{R}=\left[\begin{array}{llll}
\rho_{11} & \rho_{12} & \rho_{13} & \rho_{14} \\
\rho_{21} & \rho_{22} & \rho_{23} & \rho_{24} \\
\rho_{31} & \rho_{32} & \rho_{33} & \rho_{34} \\
\rho_{41} & \rho_{42} & \rho_{43} & \rho_{44}
\end{array}\right]
\end{gathered}
$$

where

$$
\begin{gathered}
\rho_{i i}=1-\left(\sum_{n=1}^{N}\left|S_{i n}^{*} S_{n i}\right|\right), \\
\rho_{i j}=-\left(\sum_{n=1}^{N}\left|S_{i n}^{*} S_{n j}\right|\right), i, j, n=1,2,3,4 .
\end{gathered}
$$

Total active reflection coefficient is one of the significant parameters to understand the merit of MIMO antenna. It provides active bandwidth of MIMO antenna. TARC value is sensitive with the phase difference between the incoming signal at the two ports. The TARC values with some different phase combinations are calculated using $(9-11)$ in [2] presented in Fig. 10.

$$
\begin{gathered}
\Gamma_{a}^{t}=\frac{\sum_{n=1}^{N}\left|b_{i}\right|^{2}}{\sum_{n=1}^{N}\left|a_{i}\right|^{2}}, \\
{[\mathbf{b}]=[\mathbf{S}][\mathbf{a}] .}
\end{gathered}
$$

Here, $a_{i}$ and $b_{i}$ stand for incident and reflected wave respectively. [a], [b] and $[\mathbf{S}]$ are incident, reflected and scattering matrix. In Fig. $10,0^{\circ}, 120^{\circ}$ and $0^{\circ}$ means incident

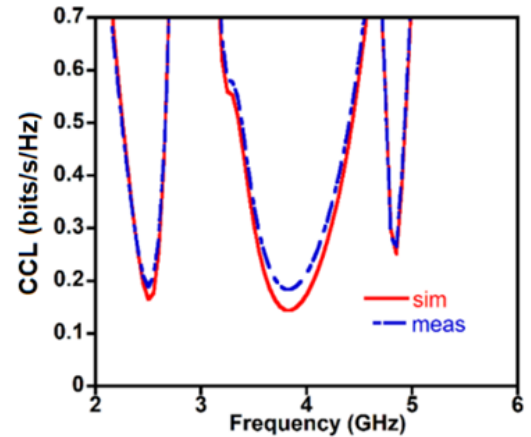

Fig. 9. CCL plots of the proposed antenna.

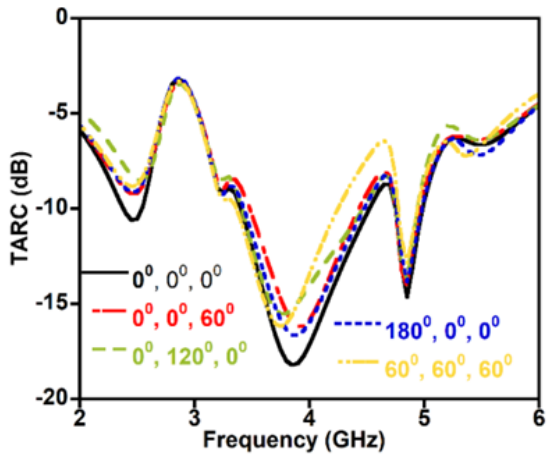

Fig. 10. TARC values with different phase combinations.

wave at antenna element $\# 2, \# 3$ and $\# 4$ are led with $0^{\circ}$, $120^{\circ}$ and $0^{\circ}$ to the antenna element $\# 1$.

$$
\left[\begin{array}{l}
b_{1} \\
b_{2} \\
b_{3} \\
b_{4}
\end{array}\right]=\left[\begin{array}{llll}
S_{11} & S_{12} & S_{13} & S_{14} \\
S_{21} & S_{22} & S_{23} & S_{24} \\
S_{31} & S_{32} & S_{33} & S_{34} \\
S_{41} & S_{42} & S_{43} & S_{44}
\end{array}\right]\left[\begin{array}{l}
a_{1} \\
a_{2} \\
a_{3} \\
a_{4}
\end{array}\right] .
$$

\section{Discussions}

\begin{tabular}{|c|c|c|c|c|c|c|}
\hline $\begin{array}{c}\text { [Ref], } \\
\text { Year }\end{array}$ & $\begin{array}{c}\text { No. of } \\
\text { bands/ } \\
\text { antenna } \\
\text { element }\end{array}$ & $\begin{array}{c}\text { Area } \\
\left(\mathrm{x} \lambda_{0} \times \mathrm{y} \lambda_{0}\right)\end{array}$ & $\begin{array}{c}\text { I } \\
(\mathrm{dB})\end{array}$ & $\mathrm{ECC}$ & $\begin{array}{c}\mathrm{CCL} \\
(\mathrm{bits} / \mathrm{s} / \mathrm{Hz})\end{array}$ & $\begin{array}{c}\text { TARC } \\
(\mathrm{dB})\end{array}$ \\
\hline $\begin{array}{c}{[14],} \\
2015\end{array}$ & $4 / 4$ & $0.69 \times 0.69$ & $\geq 20$ & $\leq 0.009$ & - & - \\
\hline $\begin{array}{c}{[8],} \\
2016\end{array}$ & $3 / 2$ & $0.30 \times 0.20$ & $\geq 16$ & $\leq 0.7$ & - & - \\
\hline $\begin{array}{c}{[6],} \\
2017\end{array}$ & $2 / 4$ & $0.32 \times 0.32$ & $\geq 20$ & $\leq 0.009$ & - & - \\
\hline $\begin{array}{c}{[7],} \\
2017\end{array}$ & $3 / 2$ & $0.2 \times 0.36$ & $\geq 15$ & $\leq 0.01$ & $\leq 0.4$ & - \\
\hline $\begin{array}{c}{[2],} \\
2018\end{array}$ & $1 / 4$ & $0.6 \times 0.6$ & $\geq 17$ & $\leq 0.3$ & $\leq 1.5$ & $\leq-6$ \\
\hline $\begin{array}{c}{[4],} \\
2018\end{array}$ & $2 / 2$ & $0.96 \times 1.03$ & $\geq 18$ & $\leq 0.21$ & $\leq 0.25$ & - \\
\hline $\begin{array}{c}{[12],} \\
2018\end{array}$ & $3 / 4$ & $0.32 \times 0.32$ & $\geq 20$ & $\leq 0.001$ & $\leq 0.30$ & - \\
\hline $\begin{array}{c}{[16],} \\
2014\end{array}$ & $2 / 4$ & $1.39 \times 1.39$ & - & - & - & - \\
\hline $\begin{array}{c}\text { This } \\
\text { work }\end{array}$ & $3 / 4$ & $0.45 \times 0.45$ & $\geq 20$ & $\leq 0.01$ & $\leq 0.25$ & $\leq-8$ \\
\hline
\end{tabular}

Tab. 1. Comparison of the proposed work with published work in literatures. 
A comparison of this work with other literatures is tabulated in Tab. 1. From the comparison table, it is observed that only [6] is more compact and offers better ECC than the proposed work. However, [6] is a dual band antenna. Design [4] has the same CCL value with the proposed design, however, it offers dual band with larger size. The antenna [14] has four elements and provides quad band. However, the size of the structure is very large compared to the proposed design. The proposed work offers better performances with respect to [2] in terms of number of bands and TARC values. It is evident that this design is more compact in size with triple band response and reasonably good MIMO characteristics.

\section{Conclusion}

This paper presents a compact triple band antenna for MIMO applications. A modified triangular ring resonator is placed inside the empty space of a split isosceles triangular ring resonator to realize the triple band response. This antenna element is used further to design a quad element MIMO antenna which offers the bands at $2.35-2.65 \mathrm{GHz}$, $3.36-4.18 \mathrm{GHz}$ and $4.80-5.00 \mathrm{GHz}$. Orthogonal arrangement of antenna element provides isolation better than $20 \mathrm{~dB}$ between two terminals which makes it suitable for MIMO applications. Diversity performances are studied to check the antenna performance as MIMO applications and these are within the acceptable limit. Radiation patterns of this antenna at three resonances are omnidirectional with a gain of $0.6 \mathrm{dBi}, 1 \mathrm{dBi}$ and $0.8 \mathrm{dBi}$ for the first, second and third resonances, respectively. Thus, this antenna is a suitable candidate for Bluetooth $(2.4 \mathrm{GHz})$, WLAN (2.5/4.9 GHz) and LTE (3.7 GHz) applications.

\section{References}

[1] SHARAWI, M. S. Printed multi-band MIMO antenna systems and their performance metrics [wireless corner]. IEEE Antennas and Propagation Magazine, 2013, vol. 55, no. 5, p. 218-232. DOI: 10.1109/MAP.2013.6735522

[2] WU, W., YUAN, B., WU, A. A quad-element UWB-MIMO antenna with band-notch and reduced mutual coupling based on EBG structures. International Journal of Antennas and Propagation, 2018, vol. 2018, p. 1-10. DOI: $10.1155 / 2018 / 8490740$

[3] NANDI, S., MOHAN, A. A compact dual-band MIMO slot antenna for WLAN applications. IEEE Antennas and Wireless Propagation Letters, vol. 16, p. 2457-2460. DOI: 10.1109/LAWP.2017.2723927

[4] MORSY, M. M., MORSY, A. M. Dual-band meander-line MIMO antenna with high diversity for LTE/UMTS router. IET Microwaves, Antennas \& Propagation, 2018, vol. 12, no. 3, p. 395-399. DOI: 10.1049/iet-map.2017.0802

[5] POUYANFAR, N., GHOBADI, C., NOURINIA, J., et al. A compact multi-band MIMO antenna with high isolation for $\mathrm{C}$ and $\mathrm{X}$ bands using defected ground structure. Radioengineering, 2018, vol. 27, no. 3, p. 686-693. DOI: 10.13164/re.2018.0686

[6] KUMARI, T., DAS, G., SHARMA, A., et al. Design approach for dual element hybrid MIMO antenna arrangement for wideband applications. International Journal of $R F$ and Microwave Computer-Aided Engineering, 2019, vol. 29, no. 1, p. 1-10. DOI: $10.1002 /$ mmce. 21486

[7] SARKAR, D., SRIVASTAVA, K. V. Compact four-element SRRloaded dual-band MIMO antenna for WLAN/WiMAX/WiFi/4GLTE and 5G applications. Electronics Letters, 2017, vol. 53, no. 25 , p. 1623-1624. DOI: 10.1049/el.2017.2825

[8] NANDI, S., MOHAN, A. CRLH unit cell loaded triband compact MIMO antenna for WLAN/WiMAX applications. IEEE Antennas and Wireless Propagation Letters, 2017, vol. 16, p. 1816-1819. DOI: 10.1109/LAWP.2017.2681178

[9] SUN, J. S., FANG, H. S., LIN, P. Y., et al. Triple-band MIMO antenna for mobile wireless applications. IEEE Antennas and Wireless Propagation Letters, 2015, vol. 15, p. 500-503. DOI: 10.1109/LAWP.2015.2454536

[10] KUMAR, A., ANSARI, A. Q., KANAUJIA, B. K., et al. Design of triple-band MIMO antenna with one band-notched characteristic. Progress In Electromagnetics Research C, 2018, vol. 86, p. 41-53. DOI: 10.2528/PIERC18051902

[11] MALVIYA, L., PANIGRAHI, R. K., KARTIKEYAN, M. V. Circularly polarized $2 \times 2$ MIMO antenna for WLAN applications. Progress In Electromagnetics Research C, 2016, vol. 66, p. 97-107. DOI: 10.2528/PIERC16051905

[12] ISLAM, S. N., KUMAR, M., SEN, G., et al. Design of a compact triple band antenna with independent frequency tuning for MIMO applications. International Journal of $R F$ and Microwave Computer-Aided Engineering, 2019, vol. 29, no. 3, p. 1-10. DOI: 10.1002/MMCE.21620

[13] ISLAM, S. N., GHOSH, A., KUMAR, M., et al. A compact dualband antenna using triangular split ring resonator for Bluetooth/WiMax/LTE applications. In IEEE Indian Conference on Antennas and Propagation (InCAP). Hyderabad (India), 2018, p. 1-3. DOI: 10.1109/INCAP.2018.8770768

[14] SARKAR, D., SINGH, A., SAURAV, K., et al. Four-element quad-band multiple-input-multiple-output antenna employing split-ring resonator and inter-digital capacitor. IET Microwaves, Antennas \& Propagation, 2015, vol. 9, no. 13, p. 1453-1460. DOI: 10.1049/iet-map.2015.0189

[15] THAYSEN, J., JAKOBSEN, K. B. Envelope correlation in (N, N) MIMO antenna array from scattering parameters. Microwave and Optical Technology Letters, 2006, vol. 48, no. 5, p. 832-834. DOI: 10.1002/mop. 21490

[16] ZHANG, T., ZHANG, Y., HONG, W., et al. Triangular ring antennas for dual-frequency dual-polarization or circularpolarization operations. IEEE Antennas and Wireless Propagation Letters, 2014, vol. 13, p. 971-974. DOI: 10.1109/LAWP.2014.2319455

\section{About the Authors ...}

Sk Nurul ISLAM (1989) received the B.Tech. degree in Electronic and Comm. Engineering from the West Bengal University of Technology, Kolkata in 2011, and the M.Tech. degree in Electronics and Communication Engineering from the West Bengal University of Technology, Kolkata in 2013. He is currently pursuing the Ph.D. degree in Microwave Engineering with the Electronics and TeleCommunication Engineering Department, Indian Institute of Engineering Science and Technology, Shibpur, Howrah, India. His current research interests include microwave plane antenna, metamaterial. 
Santanu DAS (1968) received the B.E. degree in Electronic and Telecommunication Engineering from the Bengal Engineering College in 1989, and the M.E. degree in Microwave Engineering from the Jadavpur University, Calcutta in 1992. He obtained the Ph.D. (Engineering) degree in the year 1998 from the Jadavpur University. As a Lecturer in Electronics and Telecommunication
Engineering, he joined the department of the Bengal Engineering and Science University in 1998 and presently holds the post of Professor at the same department. His current research interests include the microstrip circuits, antenna elements and arrays, FSS and defected ground structures. He is a life member of the Institution of Engineers, India. 